\title{
Plano Nacional de Ordenamento do Território: O máximo denominador comum
}

Isabel Guerra*

\begin{abstract}
$\mathrm{R}$ Lesumo: Este artigo discute o Plano Nacional de Ordenamento do Território, enquandrando-o como um instrumento marcante para o planeamento territorial português, sendo o primeiro instrumento que apresenta para o território nacional uma visão coerente e integrada nas suas várias componentes (fundiárias, ambientais, económicas, sociais ou de mobilidade). Considera-se que se trata de um plano politicamente sedimentado, que é apresentado como um documento estruturador e transversal a um conjunto de políticas parcelares com impacte territorial: da dotação de infra-estruturas às grandes vias e modos de transporte, da protecção ambiental à reestruturação dos equipamentos sociais e culturais.

No entanto, o PNPOT evita tratar algumas das questões decisivas - e polémicas - do sistema de ordenamento territorial, com particular realce para a actual partição administrativa, a repartição de competências entre os vários níveis da administração ou as formas de gestão e fiscalização da execução de um plano tão ambicioso.

O momento de discussão pública estimula sobretudo a análise crítica capaz de tornar a proposta do PNPOT num documento suficientemente fundamentado e programado e eficazmente gerido.
\end{abstract}

Palavras-chave: Planeamento; Território; PNPOT.

\section{Introdução}

A tese deste artigo sobre o Plano Nacional de Ordenamento do Território, redigido na fase da sua discussão pública e situando-se como um contributo para essa discussão, enquadra-o como instrumento determinante do planeamento territorial português, sendo o primeiro instrumento que apresenta para o território nacional uma visão coerente e integrada nas suas várias componentes (fundiárias, ambientais, económicas, sociais ou de mobilidade). Trata-se ainda de um plano politicamente sedimentado, aprovado em Conselho de Ministros, e apresentado como um documento estruturador e transversal a um conjunto de políticas parcelares com impacte territorial: da dotação de infra-estruturas às grandes vias e modos de transporte, da protecção ambiental à reestruturação dos equipamentos sociais e culturais.

No entanto, nesta discussão crítica do PNPOT, é fundamental evidenciar e analisar algumas das questões decisivas - e polémicas - do sistema de ordenamento territorial que não são abordadas no documento, com particular realce para a actual partição administrativa, a repartição de competências entre os vários níveis da administração ou as formas de gestão e fiscalização da execução de um plano tão ambicioso.

O momento de discussão pública estimula, sobretudo, a análise crítica capaz de tornar a proposta do PNPOT num documento suficientemente fundamentado e programado e eficazmente gerido.

\section{Enquadramento europeu do PNPOT ou o esquecimento das questões da organização do espaço comunitário}

A reflexão e a definição de uma política europeia de planeamento territorial tem sido tímida, reflectindo-se num impacte pouco significativo em Portugal $^{1}$. De facto, na Europa, a ausência de

\footnotetext{
* Professora do Departamento de Sociologia do ISCTE, investigadora do CET. Contacto: isabel.guerra@iscte.pt

Sobre este impacte ver o artigo de Artur Rosa Pires, The fragile Foundationd of European Spatial Planning in Portugal, European Planning Studies, vol. 13, n." 2, Maŗ̧o de 2005, pp. 237-252.
} 
competências formais no campo do planeamento territorial tem sido impeditiva de uma posição mais clara e interventiva, quer ao nível do espaço europeu como um todo, quer ao nível das orientações para os Estados-Membros.

No entanto, este não comprometimento não impediu a produção de documentos de grande importância para a organização do espaço europeu. A discussão sobre a necessidade de propor um modelo de desenvolvimento territorial integrado emerge em Nantes, em 1989, na primeira reunião dos ministros europeus responsáveis pelo planeamento territorial. Segundo Faludi e Waterhout (2002), a França, a Holanda e a Alemanha foram os países que se mostraram mais activos na elaboração de propostas para um modelo espacial europeu, por vezes em competição entre si, tendo-se destacado a versão francesa que, através de uma grande experiência em "aménagement du territoire", colocou as grandes questões e as dimensões estruturantes do que viria a ser o ESPD (CEC, 1997), e onde se destacou em 1999 a produção de um documento de orientações estratégicas - o Euro- pean Spatial Developement Perspective (ESPD, CE, $1999^{2}$ ).

Os países mediterrâneos foram acusados de pouco interessados e, até, de terem intenções de boicote a esta iniciativa, o que se tratou, segundo Rivolin e Faludi (2005), de uma acusação injusta, pois a menor adesão desses países teria origem em três receios fundamentais. i) o reforço da blue bana e uma maior periferização dos países do sul; ii) a potencial retirada de alguns territórios do Objectivo 1 e, finalmente, iii) os países do "grupo mediterrâneo " teriam ainda medo que a forte regulação de um potencial plano estratégico fosse demasiado constritiva, defendendo que teriam a divergent style of policy-making, perceba-se, uma desregulação característica das formas de gestão territorial do Sul.

O ESPD foi um documento realizado por peritos europeus e pouco ancorado na administração dos países europeus, embora tenha sido subscrito por 15 Estados-Membros (entre os quais Portugal), que se comprometeram a "aplicar" estas directivas. Apesar dessa aprovação, Pires (2005)

Fig. 1

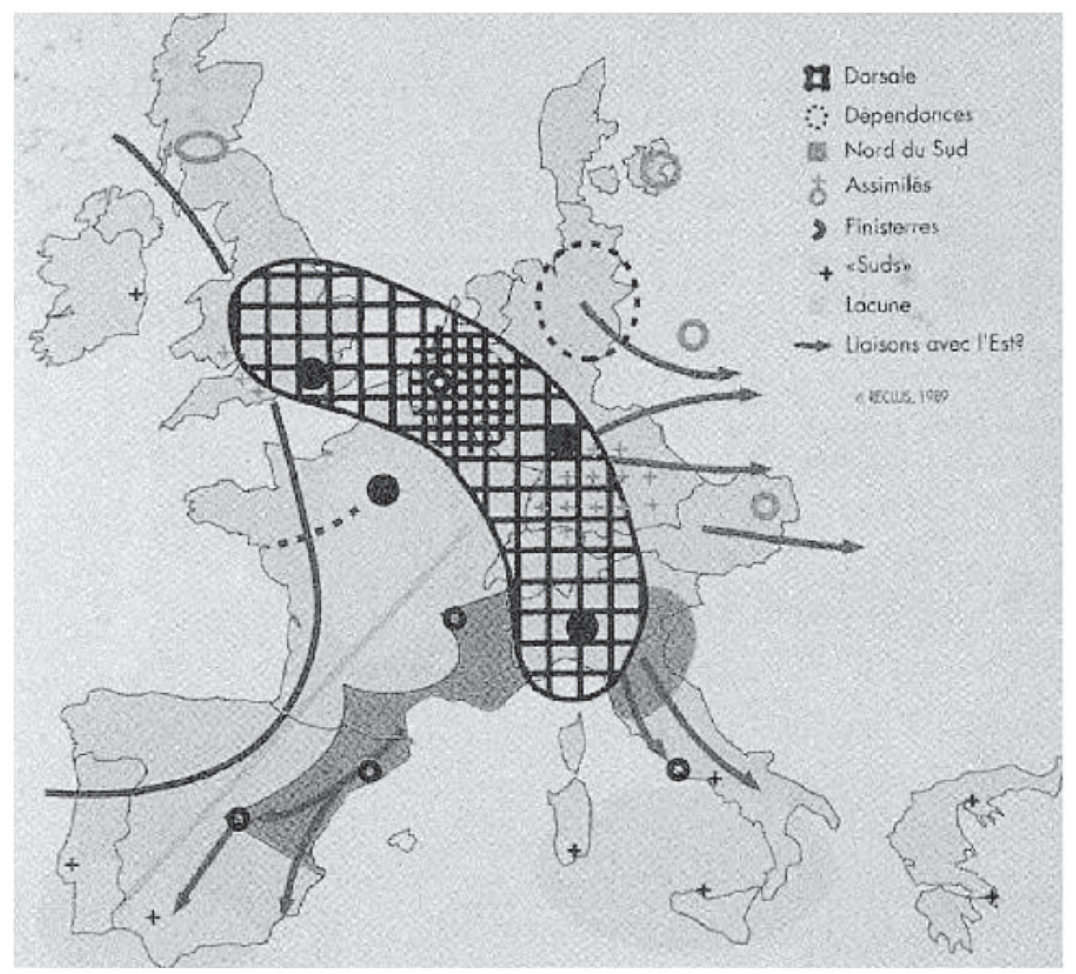

The 'Blue Banana'. Fonte: Reclus, 1989

${ }^{2}$ Ver http://ec.europa.eu/regional_policy/sources/docoffic/official/reports/pdf/sum_en.pdf e
http://ec.europa.eu/regional_policy/sources/docoffic/official/reports/pdf/concl_en.pdf. 
considera que "O ESPD está longe de ter ocupado uma posição predominante na agenda de discussão dos profissionais de planeamento em Portugal" (p. 237), reconhecendo ainda que o documento estabiliza valores e apostas estratégicas globais características de qualquer plano de desenvolvimento territorial moderno, influenciando, por isso, a matriz de trabalho dos vários países europeus.

Os objectivos do ESPD são os de reforçar a cooperação entre países e regiões visando: i) desenvolver pólos económicos e sociais transfronteiriços de forma a elaborar estratégias de desenvolvimento durável; ii) cooperar para integrar as regiões europeias numa rede coerente de cidades e regiões; e iii) melhorar a eficácia das políticas de coesão e os modos de desenvolvimento regional através da criação de redes, com particular destaque para as regiões em crise e/ou reconversão.

O ESPD não define competências europeias na organização territorial, mas pretende ser um marco de orientação e de adesão voluntária dos Estado-Membros, com base em princípios que são hoje indiscutíveis em qualquer processo de planeamento territorial, agora olhados no contexto europeu:

- Desenvolvimento policêntrico, estabelecendo novas e vigorosas relações entre campo e cidade;

- Acesso equitário a infra-estruturas e qualidade de vida em todo o espaço comunitário;

- Gestão acautelada dos recursos naturais; considerados como base essencial do desenvolvimento sustentável, salvaguardando particularmente a gestão criativa de paisagens e patrimónios culturais.

\section{PNPOT e as novas políticas públicas portuguesas}

Portugal prepara-se para negociar um novo Quadro Comunitário (2007/2013) e estabiliza os principais documentos de enquadramento, donde se destaca como principal figura a Estratégia Nacional para o Desenvolvimento Sustentável (ENDS). A ENDS tem uma longa história que se inicia no Governo do Dr. Durão Barroso, passa pelo do Dr. Santana Lopes e termina, já muito reformulada, no Governo do Eng. ${ }^{\circ}$ José Sócrates com a publicação de uma nova versão da ENDS, apresentada, em Dezembro de 2005, por uma equipa liderada por Carlos Zorrinho.
O documento pretende enquadrar o "desenvolvimento sustentável” de Portugal para o próximo período comunitário e estabelece como "desígnio mobilizador tornar Portugal num dos países mais competitivos e atractivos da União Europeia, num quadro de elevado desenvolvimento económico, social e ambiental e de responsabilidade social e define como objectivos a prosseguir para os três pilares do desenvolvimento sustentável (Protecção e Valorização do Ambiente, Coesão Social e Desenvolvimento Económico)".

Este documento pretende ser um documento enquadrador e prevê que a estratégia seja detalhada por mais 4 planos nacionais: O PNACE - Programa Nacional de Acção para o Crescimento e o Emprego; o QREN - Quadro Comunitário de Referência Estratégica; o PNPOT - Programa Nacional da Política de Ordenamento do Território, o PNAC - Plano Nacional para as Alterações Climáticas.

Neste contexto, nada seria mais adequado do que publicar e colocar em discussão pública um documento que materializa no espaço português essas políticas. O enquadramento jurídico classifica o Programa Nacional da Política de Ordenamento do Território como "instrumento chave na articulação entre as políticas de ordenamento do território e de desenvolvimento económico e social" devendo estruturar as estratégias fundamentais do ordenamento espacial, mas também as que correspondem aos equipamentos, acessibilidades e outras políticas públicas (Decreto-Lei n. ${ }^{\circ} 380$ / /99 de 22 de Dezembro). O objectivo é fornecer uma visão orientadora e coerente sobre a organização espacial do sistema urbano que oriente não só a localização das infra-estruturas, como a intervenção nas áreas do ambiente e das restantes políticas públicas, tornando-se um elemento central para enquadrar os programas operacionais que se avizinham.

Como é explicitado nos contributos das Ordens profissionais dos Engenheiros e dos Arquitectos que acompanharam a realização do PNPOT, este deverá ser aprovado - depois da fase de discussão pública - cerca de 10 anos depois das Grandes Opções do Plano terem sugerido a sua elaboração, em 1996. Elaborado durante muito tempo, e através de um processo que alguns criticam por secretismo, o documento tem uma estrutura clássica, situando Portugal no Mundo, analisando as tendências recentes de organização do território geral e regional e propondo a estratégia 
para um modelo territorial com o horizonte temporal de 2025.

Como é apanágio dos processos de planeamento, o PNPOT inicia-se por um diagnóstico onde identifica os principais problemas da organização territorial portuguesa:

a) Insuficiente salvaguarda e valorização dos recursos naturais e ineficiente gestão dos recursos;

b) Expansão urbana desordenada e correspondentes efeitos na fragmentação e desqualificação do tecido urbano e dos espaços envolventes;

c) Ineficiência e insustentabilidade ambiental e económica no domínio dos transportes e da energia;

d) Insuficiência das infra-estruturas e sistemas de apoio à competitividade, conectividade e projecção internacional da economia do país;

e) Inadequação da distribuição territorial de infra-estruturas e de equipamentos colectivos face às dinâmicas de alteração do povoamento e das necessidades sociais; e

f) Ausência de uma cultura cívica de ordenamento do território e ineficiência dos sistemas de informação, planeamento e gestão territorial.

O documento define como objectivos:

a) Preservar o quadro natural e paisagístico, em particular os recursos hídricos, a orla costeira, a floresta e os espaços de potencial agrícola;

b) Gerir e valorizar as áreas classificadas integrantes da Rede Fundamental de Conservação da Natureza;

c) Articular o sistema de "espaços abertos" de natureza ambiental e paisagística com o sistema urbano e as redes de infra-estruturas; e

d) Estruturar nucleações que contrariam a tendência para a urbanização continua ao longo da faixa litoral.

Alguns anos antes da sua elaboração, e na sequência do Decreto-Lei n. ${ }^{\circ} 380 / 99$ de 22 de Dezembro que o enquadra, Amaro Alves (1999) considera duas funções fundamentais do PNPOT: "A primeira, consiste em orientar a intervenção do Estado sobre a organização do território, onde releva o carácter horizontal e plurisectorial dessa intervenção e sobrepõe os princípios da coordenação, da articulação e da convergência nas actividades dos diferentes departamentos do Estado. A segunda, consiste em dar a conhecer as intenções do Estado aos outros agentes que intervêm também na organização do território para que possam decidir de forma mais segura sobre as questões que representam opções de localização no território, de acordo com os seus anseios, necessidades e valores, onde se afirmam os princípios da informação, da participação e da responsabilidade partilhada" (p. 5). O autor continua sugerindo que "o PNPOT enquanto instrumento de desenvolvimento territorial, terá que conter três dimensões: 1) as opções do Estado das diferentes políticas públicas em termos de localização no espaço (território), ii) as prioridades de execução das diferentes políticas em termos de localização no tempo, iii) os esquemas de articulação e de concentração no espaço e no tempo entre as diferentes políticas" (p. 5)

\section{As opções do PNPOT: virtualidades e críticas}

A recepção maioritariamente positiva deste documento por parte de políticos e decisores e técnicos não é alheia ao facto da sua concepção ter sido feita por uma equipa de Ministério e Secretaria de Estado liderada por especialistas de elevada competência, e com compromissos claros com o desenvolvimento e a equidade territorial. Também todos os que se dedicam ao planeamento territorial conhecem a diversidade de posturas e de interesses que minam este terreno, a complexa rede de enquadramentos legislativos e de compromissos anteriores e apreciam o facto de ser a primeira vez no urbanismo português que se coloca em discussão pública um documento cuja transversalidade e necessidade de integração de perspectivas exigiu necessariamente um esforço de articulação e de negociação, cujas dificuldades se adivinham e prevêem ainda.

A importância atribuída ao documento advém ainda da sua aprovação ter sido feita em Conselho de Ministros, sendo assumido como responsabilidade de um Governo e não apenas de um Ministério ou Secretaria de Estado, num momento oportuno em se debatem, em simultâneo, os PROTS e Planos Estratégicos Regionais.

O PNPOT é um documento de grande fôlego assumindo opções face ao modelo territorial que 
são exemplares pela defesa coerente e articulada de "um território policêntrico", com o reforço das articulações urbano-rurais que estruturam as restantes medidas propostas.

\section{Propostas de estruturação territorial no PNPOT}

O PNPOT, quando olhado genericamente, apresenta-se complexo, polivalente e multidisciplinar, incluindo análises e propostas de uma grande diversidade de dimensões de impacte territorial (ambiente, comunicações, vilas e cidades, etc.), mas também de formas de governação ou de instrumentos e formas de planeamento.

Uma outra virtualidade do PNPOT que interessa referenciar, relativamente rara na administração, diz respeito ao processo de participação alargada. Uma vez saído do secretismo onde esteve mergulhado tanto tempo, entrou em discussão pública e são muito os actores institucionais, e individuais, de vária índole, que estão no actual período a registar as suas críticas e sugestões, em momentos públicos de debate colectivo ou por registo individual no site.

É nesse sentido que se considera que este é um documento esforçado, que sintetiza no hic et nunc do jogo sociopolítico português as opções face a um modelo de organização do "sistema urbano", emergindo como um máximo dos acordos possíveis entre a enorme variedade e conflitualidade de interesses nacionais, regionais e municipais que atravessam o território e a sua administração.

\section{Mais um contributo para o debate}

Os comentários que aqui se apresentam aproveitam pois este período de debate público do PNPOT, não destacando sobretudo a análise crítica do seu conteúdo, mas, das ausências que parecem essenciais num processo estratégico de ordenamento territorial eficaz.

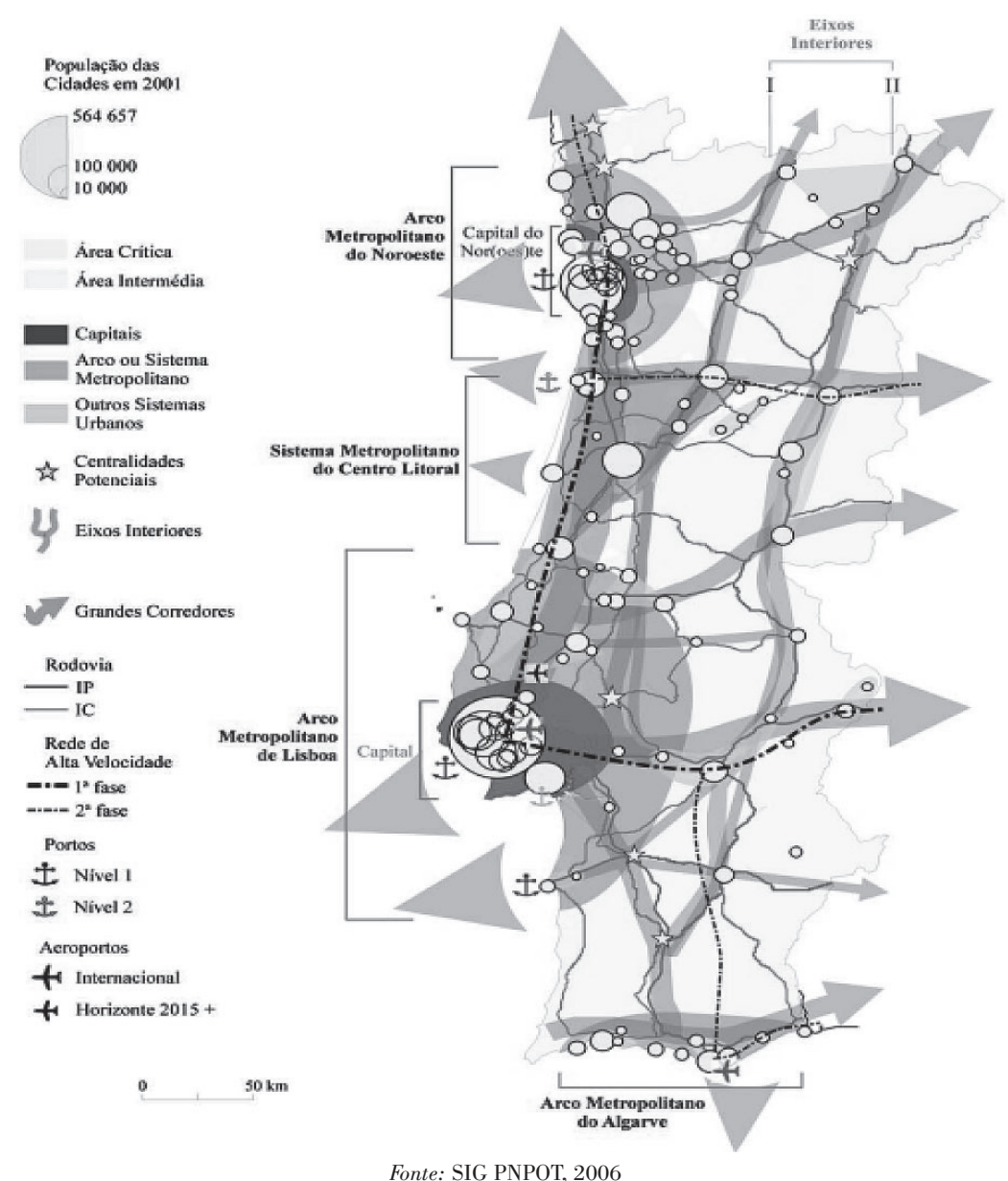

Figura 2: Sistema urbano, acessibilidades e povoamento 


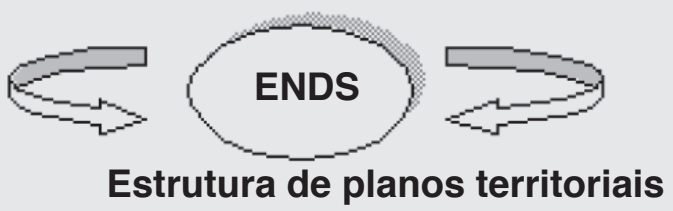

PLANO NACIONAL DE POLÍTICA DE ORDENAMENTO DO TERRITÓRIO

\begin{tabular}{|c|}
\hline $\begin{array}{l}\text { Planos Sectoriais } \\
\text { Rede Natura } \\
\text { Plano Nacional de } \\
\text { Regadios } \\
\text { Plano Rodoviário Nacional } \\
\text { Plano Nacional da Rede } \\
\text { Hospitalar } \\
\ldots\end{array}$ \\
\hline $\begin{array}{l}\text { Estratégias e Programas } \\
\text { de Âmbito Sectorial: } \\
\text { Gestão Integrada da Zona } \\
\text { Costeira Nacional } \\
\text { Programa Nacional de } \\
\text { Recuperação e Valorização da } \\
\text { Paisagem } \\
\text { Estratégia de Desenvolvimento } \\
\text { Regional } \\
\text {.... }\end{array}$ \\
\hline
\end{tabular}

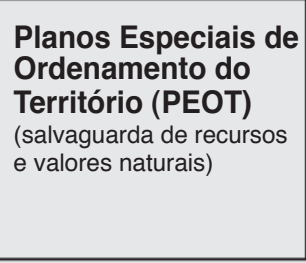

\begin{tabular}{|l|}
\hline Planos Regionais \\
de \\
Ordenamento \\
do \\
Território (PROT) \\
\end{tabular}
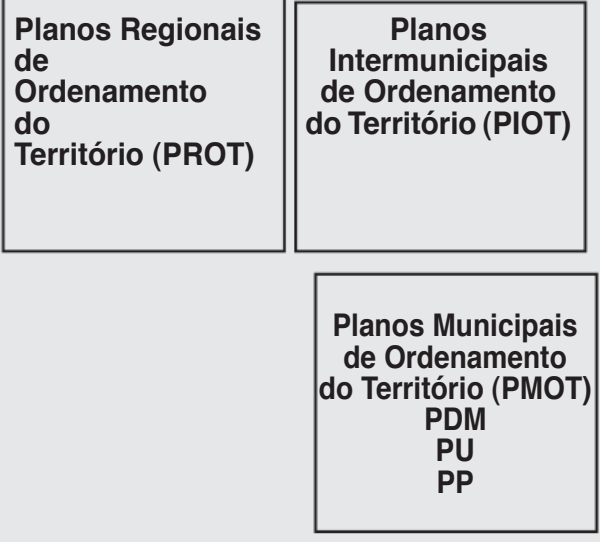

Figura 3: Estrutura de Planos Territoriais

\section{Que tipo de plano é o PNPOT?}

Esta proposta de PNPOT opta por um plano extensivo que tem a virtualidade de todos se sentirem representados, quer estejam a trabalhar no ambiente, no sistema produtivo, nas mobilidades ou na coesão social. Mas essa extensão é, apesar de tudo, inimiga de algum aprofundamento estratégico.

De facto, temos tradicionalmente duas figuras de plano - o "grande plano" e o "plano estratégico". No primeiro caso, a perspectiva é a do recenseamento das medidas em curso ou projectadas na tentativa de as tornar coerentes e integradas, mas não inova nem propõe dimensões que não decorram das perspectivas do passado. No segundo caso, arrisca-se um pensamento mais prospectivo e orientador de políticas parcelares em função de dimensões estruturantes que podem não estar presentes mas se consideram ser estratégicas. $\mathrm{Na}$ elaboração do PNPOT houve uma opção mais próxima do primeiro modelo.

Fazendo a distinção entre plano e programa, Amaro Alves (1999) escreve, ainda antes do PNPOT ser apresentado: “O PNPOT pode ser visto como um somatório das políticas sectoriais em curso e neste caso trata-se apenas de uma estratégia que procura fazer convergir objectivos e meios e o resultado final é uma proposta de organização espacial que derivada de opções já formuladas. Esta estratégia corresponde a uma posição mais consensual com os processos de planeamento implantados e que não gera grande controvérsia. Trata-se apenas de dizer e fazer o que tem sido feito até aqui mas de uma forma diferente. Uma outra perspectiva será a de conceber uma estrutura territorial ideal mas realista, ancorada na Constituição da República e com base em princípios de desenvolvimento sustentável, que passe pelo estabelecimento de critérios objectivos operacionais (no tempo e no espaço) nas diversas componentes que o compõem, para de seguida verificar em que medida políticas em curso, encaixam ou não nesta estrutura territorial, resultando a partir dele diversas propostas sectoriais. Trata-se de uma posição diferente da anterior, que certamente irá gerar maiores implicações e reajustamentos nas políticas em curso e por isso mais controversa" (p. 6)

O PNPOT parece optar pela primeira lógica, tendo um olhar pouco estratégico e mais descritivo, parecendo excessivamente preocupado em contemplar todos os olhares e áreas de intervenção. 
Para que fosse considerado um plano estratégico seria necessário responder à questão: o que realmente está em causa no território português que na próxima década deveria estar resolvido e em que sentido deverão apontar as opções? Isto é, quais são os problemas e o que se vai fazer, sabendo que não é possível colocar todas as acções na mesma ordem de prioridades?

Pode colocar-se como hipótese mais plausível que esta opção por um plano mais descritivo não se deve a uma escolha técnica, mas sim a uma impossibilidade política de conseguir eleger áreas fundamentais - geralmente pouco consensuais para estruturar estrategicamente o Plano. Sendo um primeiro esforço de sistematização e consenso, tornou-se provavelmente necessário esvaziar o plano de dimensões que impedissem a sua aprovação em tempo útil.

Mas é preciso reconhecer que estas dificuldades potenciais deixam de fora questões fundamentais para uma nova geografia de Portugal em que o documento é omisso. São exemplo disso:

- A partição regional portuguesa, não propondo ou comentando um "mapa das regiões" ou mesmo a participação municipal e regional existente (descoordenada e até mesmo considerada por muitos como caótica);

- A descentralização e a definição de competências entre os níveis locais, regionais e nacionais não são abordados;

- E também algumas questões transversais, mas fundamentais na implementação do Plano são omissas, como a descentralização e clarificação das formas de gestão de fundos comunitários orientados para as estratégias definidas, o aprofundamento dos instrumentos de planeamento municipal ou as orientações para o financiamento dos municípios.

A opção por um documento estratégico exigiria uma legitimidade política e institucional que teria de ultrapassar um Ministério e ainda mais uma Secretaria de Estado, pressupondo um envolvimento profundo e multifuncional das várias esferas de decisão, de forma a ter um olhar integrado multi- dimensional e complexo. Mas mesmo uma opção mais descritiva, para ser eficaz, exige uma clara hierarquia das prioridades de intervenção.

\section{Um documento e um programa}

O PNPOT é constituído formalmente por dois documentos: um documento estratégico e um programa de acção com os objectivos e medidas prioritárias, sendo importante questionar estes documentos, sobretudo o programa de acção, à luz da eficácia do planeamento, constatando debilidades na formulação dos objectivos e das medidas (na clareza, na objectividade e na precisão das metas) ou na sua previsão financeira que os permita executar.

Sendo os objectivos gerais claros, os objectivos mais operacionais do ponto de vista sectorial e territorial, bem como as metas a atingir estão indefinidas. Algumas das críticas mais consistentes $^{3}$ referenciam precisamente a ausência de metas e de indicadores objectivos, capazes de monitorizar e avaliar a concretização das medidas propostas, nomeadamente no que se refere ao equilíbrio das estruturas de povoamento, implantação de equipamentos e de infra-estruturas, bem como qualidade de vida e desenvolvimento económico, social e ambiental. Igualmente, não está ainda previsto um quadro financeiro para o período em curso, sustentado em acordos dos vários ministérios e autarquias, o que permitiria analisar a sua viabilidade política e financeira.

\section{Coesão territorial e PNPOT}

Se é um facto que, do ponto de vista genérico não se pode deixar de concordar com a estrutura de sistema urbano, acessibilidades e povoamento propostos, bem como os 6 objectivos estratégicos e, particularmente, os mais associados às dimensões de qualidade de vida e coesão social e territorial, não é menos verdade que olhado pela óptica parcelar mais especializada - economia, mobilidade, coesão, etc. - cada área disciplinar sentirá insatisfação pelo carácter inevitavelmente generalista do plano.

É importante situar a análise das dimensões sociais como transversal a todas as dimensões de

\footnotetext{
${ }^{3}$ Ver, por exemplo, as críticas das Ordens dos Arquitectos, dos Engenheiros e da Associação de Urbanistas.
} 
desenvolvimento, sejam elas económicas, ambientais, relativas a recursos humanos, etc. Nesse sentido, não é particularmente preocupante a não existência de capítulo específico que aborde as dimensões da coesão social, dimensões essas que são transversais praticamente a todo os objectivos estratégicos que estão definidos e que se encontram dispersas, expressas em propostas do tipo:

- "equilibrar as condições e qualidade de vida dos territórios urbanos e rurais";

- "programas de incentivo ao arrendamento, reabilitação de zonas degradadas, apoio à mobilidade residencial";

- "distribuição de equipamentos escolares, de saúde, de cultura e lazer, etc";

- "desenvolver programas que favoreçam a integração social e urbana dos grupos sociais mais vulneráveis face à pobreza e à exclusão social (intervenções locais, redes sociais, equipamentos sociais, desportivos, serviços de proximidade de segurança)";

- "dinamizar patrimónios e culturas de expressão artística";

- "apoiar as mobilidades acessibilidades e segurança urbana";

- etc.

No entanto, a falta de uma leitura específica face às questões da coesão social na cidade e, sobretudo, sobre o impacte territorial das dimensões de discriminação e exclusão social, fragiliza o documento. A problemática das zonas urbanas críticas, das periferias sem qualidade, o envelhecimento demográfico e o seu impacte sobre a cidade, o mal-estar e a violência urbana são temas de grande actualidade e tão estreitamente articulados com a qualidade de vida urbana que não podem ser ignorados na sua especificidade. Nas medidas propostas estas questões encontram, de uma forma ou outra, programas que se lhe ajustam, mas a questão social na cidade tem pouca visibilidade e parece menos importante do que efectivamente é. Estas questões são referenciadas de um modo pouco aprofundado e não são verdadeiramente de responsabilidade de ninguém, deixando uma preocupação: quem vai agir face a estas questões com o recuo do Estado e a crise das finanças autárquicas?

\section{Que formas de concretização do PNPOT?}

Um plano territorial tem impacte numa miríade alargada de políticas e só é efectivo se for subscrito pela diversidade de ministérios e autarquias que se comprometem a executá-lo. Não é por acaso que quando os países têm um Ministério das Cidades, este é transversal e depende directamente do primeiro-ministro. Podemos pois interrogar quais são as condições de concretização efectiva deste plano do ponto de vista da sua coordenação.

Conhecem-se muitos bons planos que fracassam exactamente pela incapacidade processual de os colocar em prática. Como diz a máxima do planeamento estratégico enfatizando a importância das dimensões processuais do planeamento: "plans are nothing planning is everything". A maioria das vezes, o planeamento exige programas e uma intervenção integrada, o que tem sido, e poderá continuar ser, difícil, dada a organização vertical, burocrática e centralizada da administração portuguesa.

Ninguém nos pode acusar de temer que este seja mais um documento de boas intenções. A tradição do planeamento em Portugal é precisamente essa. Pires (2005), fazendo uma breve história da evolução do pensamento sobre o planeamento territorial em Portugal, escreve "Acima de tudo parece haver um paradoxo entre a emergência crescente de um sistema de planeamento (até certo ponto reflectindo crescentes expectativas acerca da contribuição do planeamento para a qualificação de trajectórias de desenvolvimento) e uma desilusão colectiva com os resultados práticos da actividade e planeamento" (p. 240).

Quem vai zelar pelo cumprimento de medidas transversais? Um ministro? O Conselho de Ministros? Um acordo entre ministros? Todos os planos multisectoriais têm como dificuldade acrescida um orçamento repartido pelos vários ministérios e uma gestão difusa, e também o PNPOT, que define o sistema de planeamento territorial, as suas funções e competências e os níveis institucionais de responsabilidade, mas ainda não conseguiu prever a sua gestão. A monitorização será realizada pelo Observatório do Ordenamento do Território e Urbanismo, mas este é um instrumento técnico 
claramente insuficiente para uma gestão adequada e eficaz, para a qual ainda se poderá questionar a organização de uma task-force com representação directa dos ministros mais directamente implicados, dependente directamente do primeiro-ministro.
No consenso generalizado do máximo denominador comum conseguido com o PNPOT, resta concretizar a etapa da sua discussão, preparar a sua concretização e gestão, acompanhar a sua monitorização. Estamos todos disponíveis. 


\section{Bibliografia}

ALVES, Rui Amaro (1999), O Programa Nacional da Política de Ordenamento do Território: uma utopia razoável, in VI Encontro Nacional da Associação Portuguesa de Desenvolvimento Regional, Braga, Julho.

ATKINSON, Rob (2001), "The emerging Urban Agenda and the European Spatial Development Perspective: towards an EU Urban Policy", in European Planning Studies, vol. 9, n. ${ }^{\circ} 3,2001$, pp. 222-254.

PIRES. Artur da Rosa (2005), "The fragile foundation of European Spatial Planning in Portugal", European Planning Studies, vol. 13, n. ${ }^{\circ}$ 2, Março de 2005, pp. 237-252.

RIVOLIN, Umberto Janin e FALUDI, Andreas Faludi (2005), "The hidden face of European spatial Planning: innovations in governance", European Planning Studies, vol. 13, n. ${ }^{\circ}$ 2, Março de 2005, pp. 196-215.

Site ESDP - http://www.espon.eu/

Site PNPOT - http.//territorioportugal.pt 